\title{
NONLINEAR AMPLIFICATIONS OF VERTICAL GROUND MOTIONS IN THE 1995 HYOGOKEN NAMBU EARTHQUAKE
}

\author{
Endi $\mathrm{ZHAI}^{1}$, Masakatsu MIYAJIMA ${ }^{2}$ and Masaru KITAURA ${ }^{3}$ \\ ${ }^{1}$ Member of JSCE, M. of Eng., Doctoral Candidate, Graduate School of Natural Science and Technology, Kanazawa \\ University (2-40-20, Kodatsuno, Kanazawa-shi 920, Japan) \\ ${ }^{2}$ Member of JSCE, Dr. of Eng., Associate Professor, Graduate School of Natural Science and Technology, Kanazawa \\ University (2-40-20, Kodatsuno, Kanazawa-shi 920, Japan) \\ ${ }^{3}$ Member of JSCE, Dr. of Eng., Professor, Dept. of Civil Eng., Kanazawa University, (2-40-20, \\ Kodatsuno,Kanazawa-shi 920, Japan)
}

\begin{abstract}
Four down-hole array records obtained during the 1995 Hyogoken Nambu earthquake are used to investigate the nonlinear characteristics of amplifications of vertical ground motions in various soils. Significant vertical accelerations were observed at some sites in this earthquake where soil deposits strongly behaved nonlinearly. The soil parameters under strong ground motions are identified by combining downhill simplex optimum method with multiple reflection theory. The nonlinear soil properties are evaluated by comparing the identified dynamic soil parameters with those under PS logging. The nonlinear seismic responses of both horizontal and vertical ground motions are calculated based on the soil parameters identified.
\end{abstract}

Key Words: the 1995 Hyogoken Nambu earthquake, vertical ground motion, nonlinear soil property, inverse analysis

\section{INTRODUCTION}

The 1995 Hyogoken Nambu earthquake has produced vertical ground motions that have even been significantly greater than the corresponding horizontal ground motions. Particularly in liquefied areas such as Port island (PI) of Kobe city the down-hole array records showed that the vertical ground motions, being different from the horizontal ground motions which damped about half during the propagations upward, amplified three times from the bedrock to the surface. Other sites such as a) Technical Research Center of Kansai Electric Power Company (TRC), in Amagasaki city; b) Kainan Port Sub-station of Kansai Electric Company (KPS), in Kainan city; and c) Takasago Power Station of Kansai Electric Power Company (TPS), in Takasago city, where the down-hole array records were obtained, also showed that the vertical ground motions were of different characteristics in propagating through various soils in comparison with the corresponding horizontal ground motions.

In past earthquakes, as vertical ground motions were usually less than horizontal ground motions, the nonlinear seismic response of vertical ground motions was seldom studied. Such significant vertical amplifications observed in the 1995 Hyogoken Nambu earthquake should arouse our motivations to investigate damage to soils and foundations, lifelines and other structures caused by strong vertical ground motions. For nonlinear amplifications of horizontal ground motions, the multiple reflection theory has been successfully applied to practice by considering the shear strain-dependencies of shear stiffness and damping constant of soils which have been evaluated by laboratory or field tests ${ }^{1)<3}$. Nevertheless the studies of dynamic soil properties such as Poisson's ratio $\nu$, Young's modulus $E$ and normal damping constant $h_{p}$ which govern the vertical ground amplifications can be seldom found. As this paper focuses on the amplification of vertical ground motions, the downhill simplex optimum method combined with both $S$ wave and $P$-wave multiple reflection theory developed by the authors ${ }^{4}$ is used to identify the dynamic soil parameters. Based on the equivalent linear method, the effects of nonlinear soil properties on amplifications of both horizontal and vertical ground motions are evaluated in this study. 


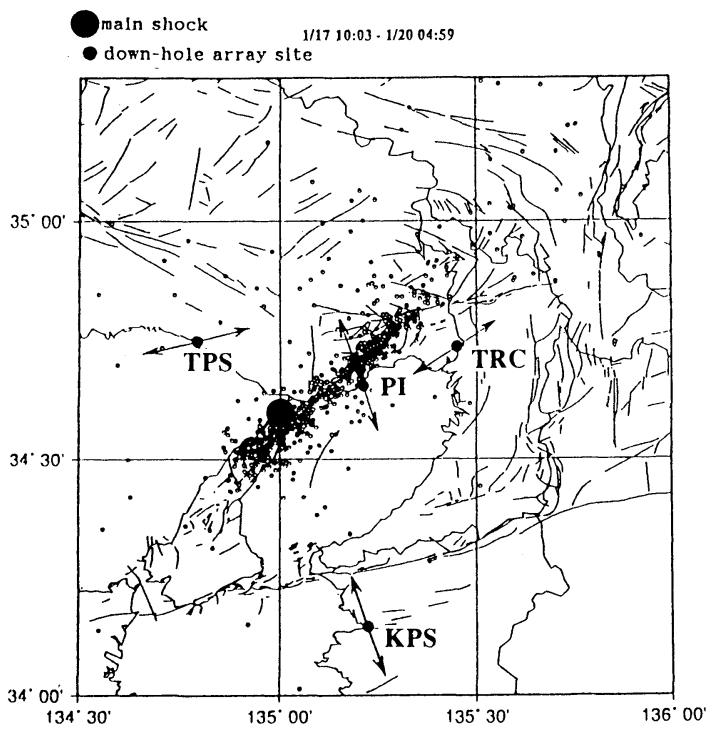

Fig.1 Location of down-hole array sites recorded around Osaka Bay and epicenters of the 1995 Hyogoken nambu earthquakc (Summarized by Disas. Prev. Res. Inst.) (After Sato ${ }^{5)}$ )

\section{SOIL PROPERTIES UNDER STRONG GROUND MOTIONS BASED ON DOWN-HOLE ARRAY RECORDS}

Fig.1 (After Sato et al. ${ }^{5}$ ) shows the locations of the four down-hole array record sites as well as the epicenter of main shock and after-shocks supplied by the Disaster Prevention Research Institute of Kyoto University. The layout of the four down-hole array records is shown in Fig.2. The amplification ratios of the recorded accelerations (Maximum acceleration of seismometer at other layer to that at the deepest layer) are also noted in Fig.2. Table 1 shows the soil profile data at the four sites where the down-hole array records were obtained. S-wave velocities in this table were measured directly by field survey. The geological conditions at the deepest layer of each site are Pleistocene gravelly soils except for the hard rock which exists at the KPS site. The upper layers consist of alternating Pleistocene gravel and clay layers, Holocene sand and clay layers, and overlaid by fill. At the PI site the upper subsoil profile is a layer $(17.5 \mathrm{~m}$ thick) of sandy fill consisting of decomposed granite.

At the PI site the amplification ratios of horizontal ground motions in both the NS and EW directions are 0.6 , but that of vertical ground motion is 3.3 . Such big reductions of maximum accelerations of horizontal ground motions at the surface are thought to be due to sandy fill layer's liquefaction. At the surface of KPS the amplification ratios of both horizontal and vertical ground motions are almost same, near 4.5. How-

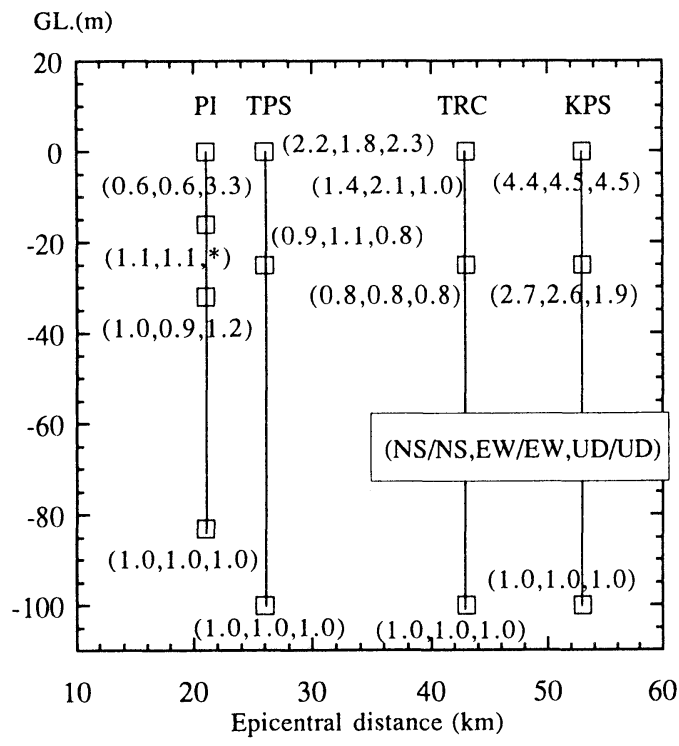

Fig.2 Layout of down-hole array observation stations and amplification ratio of maximum accelerations

ever, at the surface of TRC, the bigger amplification ratio of horizontal ground motions is 2.1 , meanwhile, that of corresponding vertical ground motion is 1.0. At TPS, the accelerations at the surface are about 2 times of those at the deepest layer for both horizontal and vertical ground motions. Such differences of amplification ratios indicate that even the same soil deposits behave quite differently between strong $S$ wave and $P$-wave propagations through them.

The recorded accelerations of the main shock of 40 seconds were base-line-revised by using the Osaki method $^{6}$, and were orientation-corrected and then applied to this study. The accelerometers used here can measure the ground vibration in frequencies from 0.1 $\mathrm{Hz}$ to $30 \mathrm{~Hz}$ and the frequency arange focused in this study is $0.1 \mathrm{~Hz}$ to $10 \mathrm{~Hz}$. For the NS and EW components of ground motions, the one having bigger maximum acceleration is used. This means that the NS component at the PI site and the EW components at the other three sites are adopted. The sampling interval of acceleration data was $\mathbf{0 . 0 1}$ second. Fig. 3 shows the ratios of Fourier amplitude spectra of corrected down-hole array acceleration records at the surface and the deepest layer of each site. To avoid singular points, the Fourier amplitude spectra were smoothed with the Parzen's window before the ratios were calculated. In order to evaluate the changes of soil properties between PS logging and the strong ground motions, the spectral amplification factors of soil deposits for both $S$-wave and $P$-wave propagations using bore-hole data were also calculated and plotted correspondingly in Fig.3 by using the present method $^{7}$. As 
Table 1 Soil profile data at the sites of down-hole records

\begin{tabular}{|c|c|c|c|c|c|c|}
\hline Site & $\begin{array}{l}\text { Depth } \\
(\mathrm{m})\end{array}$ & $\begin{array}{c}\text { Unit } \\
\text { Weight } \\
\left(\mathrm{t} / \mathrm{m}^{3}\right) \\
\end{array}$ & $\begin{array}{c}S \text {-wave } \\
\text { velocity } \\
V_{S}(\mathrm{~m} / \mathrm{s})\end{array}$ & $\begin{array}{c}\text { Poisson } \\
\text { ratio }\end{array}$ & $\begin{array}{c}\text { Mean } \\
N \text {-value }\end{array}$ & $\begin{array}{c}\text { Soil } \\
\text { Type** }\end{array}$ \\
\hline 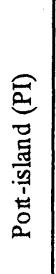 & $\begin{array}{l}0-2.0 \\
2.0-5.0 \\
5.0-12.6 \\
12.6-19.0 \\
19.0-27.0 \\
27.0-33.0 \\
33.0-50.0 \\
50.0-61.0 \\
61.0-79.0 \\
79.0-85.0\end{array}$ & $\begin{array}{l}1.7 \\
1.9 \\
1.9 \\
1.9 \\
1.7 \\
1.9 \\
1.9 \\
1.9 \\
1.7 \\
2.0\end{array}$ & $\begin{array}{l}170 \\
170 \\
210 \\
210 \\
180 \\
245 \\
305 \\
350 \\
303 \\
320\end{array}$ & $\begin{array}{l}0.127 \\
0.319 \\
0.461 \\
0.490 \\
0.488 \\
0.482 \\
0.479 \\
0.475 \\
0.482 \\
0.487\end{array}$ & $\begin{array}{l}5.2 \\
5.2 \\
6.5 \\
6.5 \\
3.5 \\
13.5 \\
36.5 \\
61.9 \\
11.7 \\
68.0\end{array}$ & $\begin{array}{l}3 \\
3 \\
3 \\
3 \\
2 \\
3 \\
3 \\
3 \\
2 \\
3\end{array}$ \\
\hline 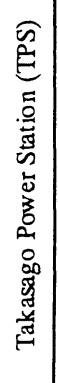 & $\begin{array}{l}0.0-3.4 \\
3.4-7.25 \\
7.25-13.4 \\
13.4-19.0 \\
19.0-25.0 \\
25.0-30.0 \\
30.0-33.0 \\
33.0-37.0 \\
37.0-44.0 \\
44.0-48.5 \\
48.5-60.0 \\
60.0-73.5 \\
73.5-81.3 \\
81.3-100.0\end{array}$ & $\begin{array}{l}1.7 \\
1.7 \\
1.6 \\
1.9 \\
1.9 \\
1.8 \\
1.7 \\
1.7 \\
1.9 \\
1.8 \\
1.9 \\
1.9 \\
1.9 \\
1.8\end{array}$ & $\begin{array}{l}140 \\
130 \\
200 \\
310 \\
400 \\
330 \\
230 \\
320 \\
560 \\
250 \\
405 \\
650 \\
500 \\
460\end{array}$ & $\begin{array}{l}0.430 \\
0.497 \\
0.492 \\
0.483 \\
0.471 \\
0.471 \\
0.480 \\
0.473 \\
0.439 \\
0.489 \\
0.470 \\
0.457 \\
0.479 \\
0.465\end{array}$ & \begin{tabular}{l|}
21.6 \\
12.8 \\
9.3 \\
38.9 \\
$79.9^{*}$ \\
45.5 \\
24.3 \\
27.6 \\
$214.3^{*}$ \\
32.8 \\
$82.9^{*}$ \\
$331.8^{*}$ \\
$153.7^{*}$ \\
$34.9^{*}$
\end{tabular} & $\begin{array}{l}4 \\
2 \\
1 \\
4 \\
4 \\
4 \\
1 \\
1 \\
4 \\
3 \\
4 \\
3 \\
4 \\
1\end{array}$ \\
\hline 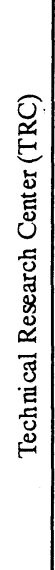 & $\begin{array}{l}0.0-2.0 \\
2.0-3.0 \\
3.0-7.0 \\
7.0-8.0 \\
8.0-11.0 \\
11.0-17.0 \\
17.0-18.0 \\
18.0-20.0 \\
20.0-30.0 \\
30.0-33.0 \\
33.0-39.0 \\
39.0-42.0 \\
42.0-45.0 \\
45.0-50.0 \\
50.0-52.0 \\
52.0-58.0 \\
58.0-60.0 \\
60.0-67.0 \\
67.0-74.0 \\
74.0-94.0 \\
94.0-97.0\end{array}$ & $\begin{array}{l}1.4 \\
1.4 \\
1.7 \\
1.7 \\
1.6 \\
2.0 \\
2.0 \\
2.0 \\
2.0 \\
1.7 \\
1.7 \\
2.0 \\
2.0 \\
2.0 \\
2.0 \\
2.0 \\
2.0 \\
2.0 \\
2.0 \\
2.0 \\
2.0\end{array}$ & $\begin{array}{l}98 \\
117 \\
117 \\
149 \\
149 \\
342 \\
222 \\
154 \\
400 \\
375 \\
375 \\
231 \\
286 \\
255 \\
177 \\
177 \\
222 \\
389 \\
333 \\
303 \\
455\end{array}$ & $\begin{array}{l}0.471 \\
0.490 \\
0.495 \\
0.494 \\
0.494 \\
0.472 \\
0.490 \\
0.495 \\
0.479 \\
0.480 \\
0.480 \\
0.488 \\
0.482 \\
0.491 \\
0.491 \\
0.487 \\
0.487 \\
0.469 \\
0.477 \\
0.481 \\
0.477\end{array}$ & $\begin{array}{l}9.3 \\
10.5 \\
10.5 \\
9.6 \\
9.6 \\
26.5 \\
17.7 \\
11.3 \\
79.9^{*} \\
66.1^{*} \\
66.1^{*} \\
24.3^{*} \\
29.9^{*} \\
21.3^{*} \\
25.0 \\
25.0 \\
29.5 \\
49.5 \\
40.0 \\
34.0 \\
116.6^{*}\end{array}$ & $\begin{array}{l}1 \\
2 \\
4 \\
3 \\
2 \\
4 \\
1 \\
3 \\
1 \\
4 \\
1 \\
1 \\
4 \\
3 \\
3 \\
1 \\
1 \\
1 \\
1 \\
1 \\
1\end{array}$ \\
\hline 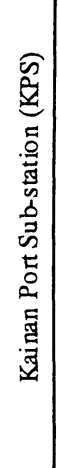 & $\begin{array}{l}0.0-1.8 \\
1.8-3.8 \\
3.8-11.0 \\
11.0-17.0 \\
17.0-23.5 \\
23.5-27.0 \\
27.0-30.0 \\
30.0-37.0 \\
37.0-39.7 \\
39.7-46.9 \\
46.9-53.4 \\
53.4-55.8 \\
55.8-61.0 \\
61.0-66.5 \\
66.5-73.9 \\
73.9-83.5 \\
83.5-100 .\end{array}$ & $\begin{array}{l}1.6 \\
1.6 \\
1.7 \\
1.6 \\
1.6 \\
1.7 \\
1.7 \\
1.6 \\
1.7 \\
1.7 \\
1.6 \\
1.8 \\
1.7 \\
1.8 \\
1.8 \\
1.7 \\
2.7\end{array}$ & $\begin{array}{l}238 \\
100 \\
177 \\
180 \\
220 \\
270 \\
188 \\
216 \\
206 \\
315 \\
263 \\
370 \\
274 \\
325 \\
700 \\
338 \\
1630\end{array}$ & $\begin{array}{l}0.446 \\
0.496 \\
0.494 \\
0.494 \\
0.485 \\
0.477 \\
0.489 \\
0.489 \\
0.496 \\
0.490 \\
0.489 \\
0.478 \\
0.488 \\
0.483 \\
0.411 \\
0.488 \\
0.395\end{array}$ & \begin{tabular}{l|}
17.0 \\
5.7 \\
19.4 \\
12.1 \\
5.0 \\
25.4 \\
20.8 \\
13.0 \\
34.3 \\
21.1 \\
26.3 \\
46.7 \\
17.3 \\
33.6 \\
32.3 \\
$48.9^{*}$ \\
$4918 . *$
\end{tabular} & $\begin{array}{l}3 \\
2 \\
3 \\
2 \\
2 \\
3 \\
3 \\
1 \\
3 \\
3 \\
2 \\
4 \\
2 \\
3 \\
4 \\
4 \\
5\end{array}$ \\
\hline
\end{tabular}

*Assumption value based on the regressional results7)

** Soil type: $1=$ clay, $2=$ silt, $3=$ sand, $4=$ gravel, $5=$ rock
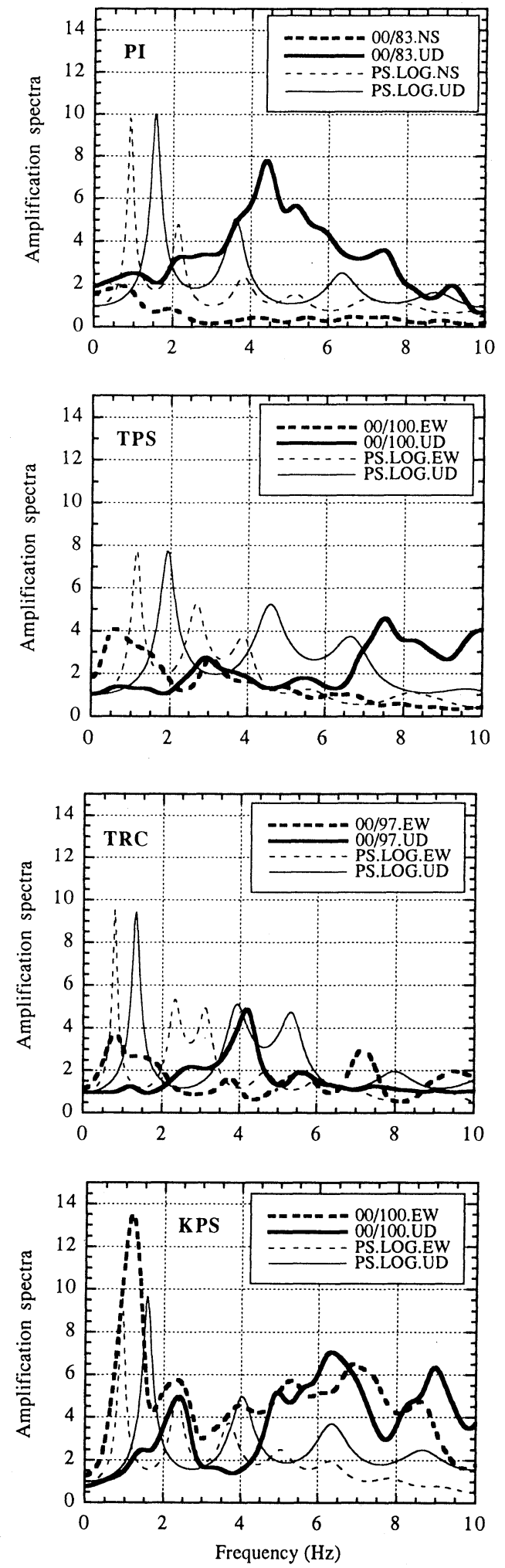

Fig.3 Amplification spectra of soil deposits under strong ground motion and PS logging 
the normal damping constants were not available, we used the shear damping constants instead of them. The shear damping constants in the present method were usually adopted from the regression formula ${ }^{7}$ as follows.

$$
h_{s}=0.017+0.0002 V_{s} \quad\left(V_{s}: \mathrm{m} / \mathrm{s}\right)
$$

The peaks of curves in Fig.3 represent the natural frequencies of the soil deposits under various ground motions. It can be observed that the soil deposits behaved significantly differently in properties: a) between small PS logging and strong earthquake ground motions; b) between horizontal and vertical ground motions of both PS logging and actual earthquake. The observations about such differences are as follows.

Under PS logging, for $S$-wave propagations from the deepest layers to the surfaces, the soil deposits at all of the four sites almost have the same predominant frequencies near $1 \mathrm{~Hz}$. But for $P$-wave propagations from the deepest layers to the surfaces, the predominant frequencies of soil deposits at all of the four sites are near $2 \mathrm{~Hz}$. It indicates that the predominant period of soil deposits under $P$-wave propagation is shorter than that under $S$-wave propagation. Although this agrees to the common knowledge, it can not explain why the natural frequencies of soil deposits under strong ground motions are even greater than those under PS logging in the vertical direction. In other words, the limit of Eq.(1) or the assumption of $h_{p}$ remain problems. Therefore, in order to deal with the nonlinear amplifications of vertical ground motions, the dynamic soil parameters under both horizontal and vertical ground motions should be properly estimated.

At all of the four sites except KPS the spectral amplification factors under strong ground motions are smaller than those under PS logging. It is then thought that the strong ground motions caused soil deposits to behave nonlinearly. Especially, at the PI site the spectral amplification factor in the horizontal direction is much smaller than that in the vertical direction. This case indicates that the soil softening, even liquefaction, does not damp the amplification of vertical ground motion more than it damps that of the horizontal ground motions. As for the KPS site, the ground motions under actual earthquake were not strong, the maximum horizontal and vertical accelerations were only $28.4 \mathrm{gal}$ and $20.0 \mathrm{gal}$ at the deepest layer, respectively. Because it was the farthest site from the epicenter among above four sites as shown in Fig.2. It can be also observed from Fig.3 that the spectral amplification factors under actual earthquake are not smaller than those under PS logging. Therefore, the soil deposits do not behave nonlinearly at the KPS site.

\section{RESPONSE INVERSE-ANALYSIS ME- THOD}

With the development of dense vertical array records of actual earthquakes, recent research has been directed towards the inverse analyses to determine dynamic soil parameters because neither laboratory test nor field probe could reproduce the dynamic soil properties subjected to actual earthquakes. Ota et al ${ }^{8)}$ used the multiple reflection theory of $S$ wave and optimum method to determine the velocity of $S$-wave and $Q$ value for the level layered ground based on the observed earthquake data at the surface and in GL-50 m. Honda et al. ${ }^{9)}$ used the finite element method and simplex optimum method to determine empirical coefficients which connected the relation of the velocity of $S$-wave and SPT $N$-value, and shear damping constant for both the level layered ground and the embankment ground. Tsujihara et al. ${ }^{10) 12)}$ and Sawada et al. ${ }^{13)}$ minimized the least squared differences between the observed and calculated ground frequency response functions to determine ground shear velocity $V_{s}$ and $Q$ value. Sato et al. ${ }^{5}$ used the down-hole array records obtained in the 1995 Hyogoken Nambu earthquake to identify $S$ wave velocity $V_{s}$ and $P$-wave velocity $V_{p}$.

This paper applied the multiple reflection theory6),7) to both $S$-wave and $P$-wave propagations and used the downhill simplex optimum method ${ }^{14), 15)}$ to firstly determine ground shear modulus $G$ and shear damping constant $h_{s}$ by minimizing the sum of squared differences between the Fourier amplitude spectra of observed and calculated horizontal accelerations, and then to determine ground Poisson's ratio $\nu$, Young's modulus $E$ and normal damping constant $h_{p}$ by minimizing the sum of squared differences between the Fourier amplitude spectra of observed and calculated vertical accelerations. For design purposes, the equivalent linear method is usually used to represent the non-linearity of ground behavior when to calculate the response of horizontal ground motion. The change of non-linearity of ground behavior in every moment can not be considered in this method. It is, however, thought that the non-linearity of ground behavior is represented in both the horizontal and vertical directions by making the dynamic soil parameters approach to their real values in convergent calculations of the objective functions.

\section{(1) Objective function of inverse analysis}

The accelerations observed at the deepest layer and at the surface or at the other layers in ground are needed to form an objective function for the optimi- 
zation during inverse-analysis. If the minimization is applied directly to the sum of squared differences between the observed and calculated acceleration time histories in the deepest layer and at the surface or at the other layers in the ground, it is possible that the error is accumulated highly because of the time lag of acceleration sampling. This paper minimizes the sum of squared differences between the Fourier amplitude spectra of observed and calculated accelerations. To let the objective function converge, the Fourier amplitude spectra between observed and calculated accelerations were smoothed with the Parzen window. $J_{h}, J_{v}$ are the objective functions minimized to determine $G, h_{s}$ and , $E, h_{p}$, respectively.

$$
\begin{aligned}
& J_{h}=\sum_{i=1}^{N_{f} / 2-1}\left(c_{h, i}-C_{h, i}\right)^{2} / \sum_{i=1}^{N_{f} / 2-1} C_{h, i}{ }^{2} \\
& J_{v}=\sum_{i=1}^{N_{f} / 2-1}\left(c_{v, i}-C_{v, i}\right)^{2} / \sum_{i=1}^{N_{f} / 2-1} C_{v, i}{ }^{2}
\end{aligned}
$$

where $C_{h, i}, C_{v, i}$ :the Fourier amplitude spectra of observed horizontal and vertical accelerations, respectively, in the $i$-th frequency; $c_{h, i}, c_{v, i}$ :the Fourier amplitude spectra of calculated horizontal and vertical accelerations corresponding to above $C_{h, i}, C_{v, i} ; N_{f}$ :sampling number.

\section{(2) Dynamic soil parameters}

To analyze the amplification of ground motions in both the horizontal and vertical directions, dynamic soil parameters such as shear modulus $G$, shear damping constant $h_{s}$, Poisson's ratio $\nu$, Young's modulus $E$ and normal damping constant $h_{p}$ must be previously determined. If we directly evaluate those parameters at each layer of soil deposits, it is likely for the objective functions not to converge due to many unknown quantities. The following empirical relations suggested by Honda et $\mathrm{al}^{9}{ }^{9}$ are applied to this study.

$$
\begin{aligned}
& V_{s}=a N^{b} \\
& G=\rho V_{s}^{2}
\end{aligned}
$$

where $N$ :SPT $N$-value; $a, b:$ the coefficients representing soil properties; $\rho$ :soil density. According to Imai $^{16)}$ and Toki ${ }^{77}, b$ can be fixed at 0.341 for soils with different properties such as sand and silt. Therefore, as long as $a$ is evaluated we can use the above relations to determine shear modulus $G$. It can be observed from convergent calculations of the objective function that the value of damping constant $h_{s}$ affects the objective function much less than the
Table 2 Identified dynamic soil parameters

\begin{tabular}{|c|c|c|c|c|}
\hline & PI & TPS & TRC & KPS \\
\hline $\mathrm{a}$ & 82.7 & 41.7 & 46.7 & 101.9 \\
\hline $\mathrm{h}_{\mathrm{s}}$ & 0.29 & 0.049 & 0.046 & 0.013 \\
\hline$\nu$ & 0.49 & 0.20 & 0.48 & 0.36 \\
\hline $\mathrm{h}_{\mathrm{p}}$ & 0.04 & 0.101 & 0.182 & 0.015 \\
\hline
\end{tabular}

value of shear modulus $G$ does. Much work has been done by Tsujihara et al. ${ }^{11)}$ to show the similar observation in this point. Therefore, to decrease unknown quantities for convergence we assume $h_{s}$ is the same in all layers at each site.

To evaluate Young's modulus $E$, the following relation is adopted.

$$
E=2(1+v) G
$$

With the identified Poisson's ratio $\nu$, the Young's modulus $E$ can be estimated. Then we assume $\nu$ and $h_{p}$ are the same in all layers at each site.

\section{AMPLIFICATIONS OF GROUND MO- TIONS USING INVERSE-ANALYSIS}

To evaluate the effects of nonlinear properties of soil deposits on the amplifications of strong ground motions at each site under the 1995 Hyogoken Nambu earthquake, the shear modulus $G$, shear damping constant $h_{s}$, Poisson's ratio $\nu$ and normal damping constant $h_{p}$ are identified with the method mentioned above. At each site the deepest layer of down-hole array of seismograph is treated as the bedrock, and the corrected recorded accelerations at the surface and the bedrock were used as input data in the convergent calculation.

Figs. 4 and 5 show the parameters $a$ and $h_{s}, \nu$ and $h_{p}$, respectively, in the processes of convergent calculations for both the horizontal and vertical ground motions at the TRC site. The values of $a$ and $h_{s}$ were stable at 46.7 and 0.046 after 20 iterations, and the values of $\nu$ and $h_{p}$ reached stable at 0.48 and 0.182 after 16 iterations, respectively. The dynamic soil parameters used to determine the amplifications of both the horizontal and vertical ground motions at all of the four sites were identified as shown in Table 2. At the PI site, the identified $a$ is not below the average regressive value ${ }^{\text {7) }}$ very much. Such small softening of 


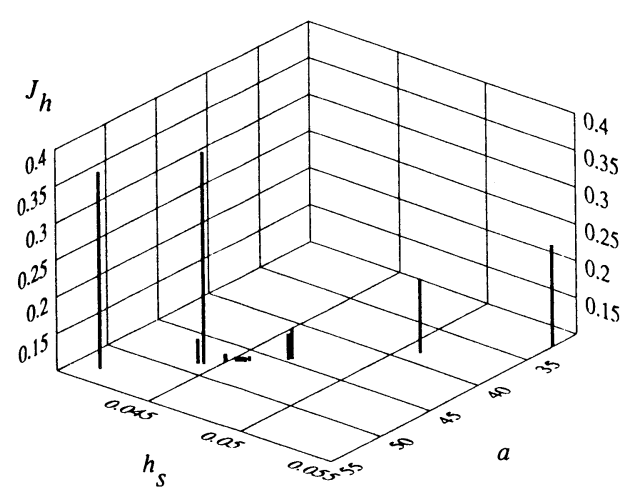

Fig.4 Convergent calculation to determine $a$ and $h_{S}$

soil deposits identified at the PI site is thought to be due to the fact that the nonlinear softening of soil deposits occurred at the PI site is dominated by liquefaction in upper sandy fill layer. The equivalent linear method used in the study is so-called Total-stress method. An effect of liquefaction in upper sandy fill layer is born by both $a$ and $h_{s}$ during the inverse analysis. As $h_{s}$ is assumed to be the same at all layers, the extreme softening of the upper sandy fill may enlarge its value to act on the whole layers. The identified $a$ at the KPS site is a little bigger than the average regressive value ${ }^{7)}$. As the recorded maximum accelerations in the horizontal and vertical directions at the KPS site were just 28.4 gal and 20.0 gal, respectively, such small ground motions have not caused nonlinear softening of soil deposits at the KPS site. The Poisson's ratio identified at each site is dominated by the natural frequencies of soil deposits under ground motions, because this study adopts Eq.(6) to constitute the relation between $G$ and $E$. Distributions of the natural frequencies of soil deposits at each site under ground motions can be seen from Fig.3. The values of $h_{p}$ identified at four sites are in correspondence with the amplification ratios of vertical ground motions as shown in Fig.2.

By using these parameters, the effect of nonlinear properties of soil deposits under strong ground motions will be considered in calculating the responses. Figs.6 and 7 show the comparisons between calculated and recorded time-histories of accelerations and their corresponding Fourier amplitude spectra at the surfaces of the four sites. The multiple reflection theory was also used here.

For all of the four sites, the calculated maximum accelerations are quite near those of the recorded except for the PI site. As for the PI site, the calculated maximum horizontal acceleration at the surface is $72.4 \%$ of that of the recorded, and the calculated maximum vertical acceleration at the surface is

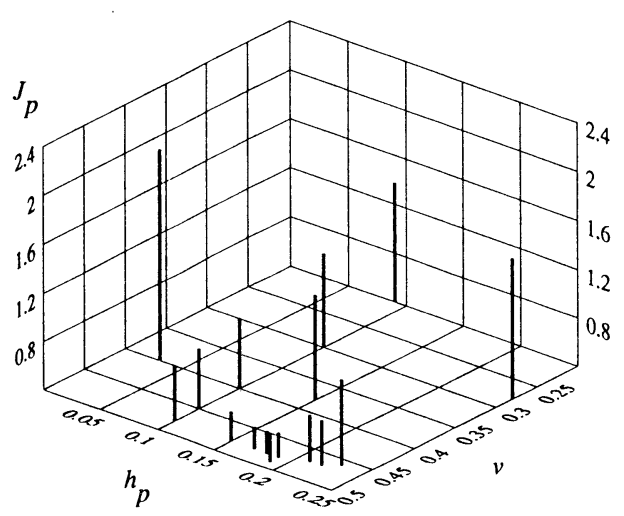

Fig.5 Convergent calculation to determine $v$ and $h_{p}$

$70.0 \%$ of that of the recorded. The reason of a trivial difference between the calculated maximum accelerations at the surface of the PI site in this paper and those in reference 4 ) is due to the different values of unit weight chosen and the correction of orientation in the deepest layer . As mentioned above, at the PI site the liquefaction in upper sandy layer affected the shear modulus and shear damping constant identified, it also affected the Young's modulus and normal damping constant identified. Accordingly it is thought that the calculated responses at the surface were less evaluated. But from a view point of engineering, such approximations show us that the equivalent linear method is effective to model even strong nonlinear soil properties.

We can find from Figs.6 and 7 that the calculated accelerations are in good shapes with the recorded ones. Meanwhile, both calculated and recorded Fourier spectra get predominant roughly in the same frequencies. As the sampling of the accelerations of main shock are cut from the 6 minutes ground motions, a link effect during the FFT transform might result in some changes in the time-histories of the calculated accelerations.

\section{IDENTIFIED NONLINEAR BEHAVIOR OF SOIL DEPOSITS UNDER STRONG GROUND MOTIONS}

The nonlinear softening behavior of soil deposits identified and the maximum strain distributions at the PI and the TRC sites are shown in Figs.8 and 9.

It can be found from Figs.8 and 9 that the softening ratios $\left(G / G_{0}\right)$ of shear modulus are almost as same as those $\left(E / E_{0}\right)$ of Young's modulus when Poisson's ratio is limited between 0 and 0.5 in convergent calculations, where $G_{o}$ and $E_{o}$ are the initial shear and Young's moduli of soil deposits determined by PS logging. These agree to the results of other two sites. 

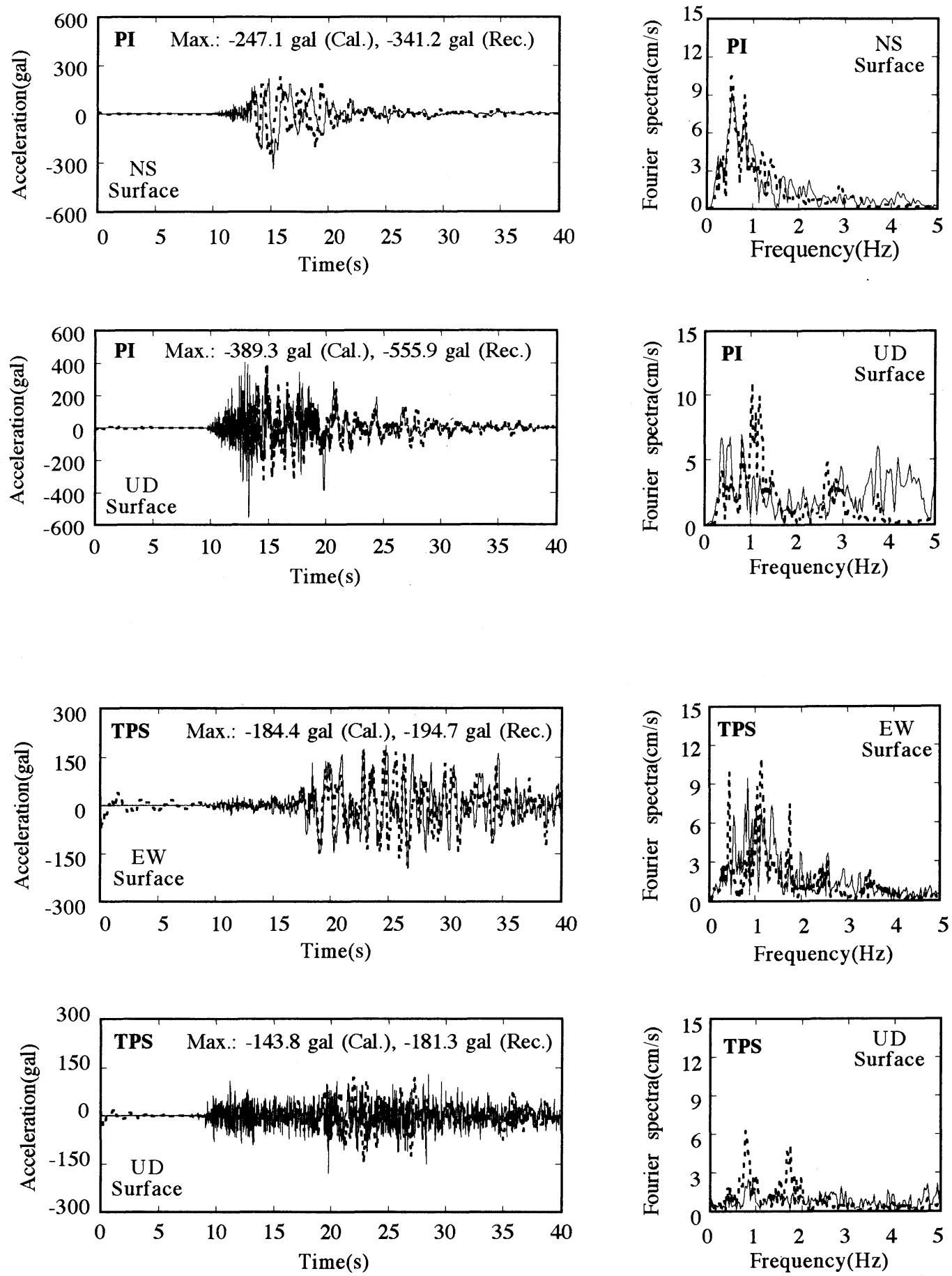

F ig. 6 Comparisons of calculated and recorded accelerations and their Fourier spectra of both horizontal and vertical ground motions at surfaces of PI and TPS sites. 

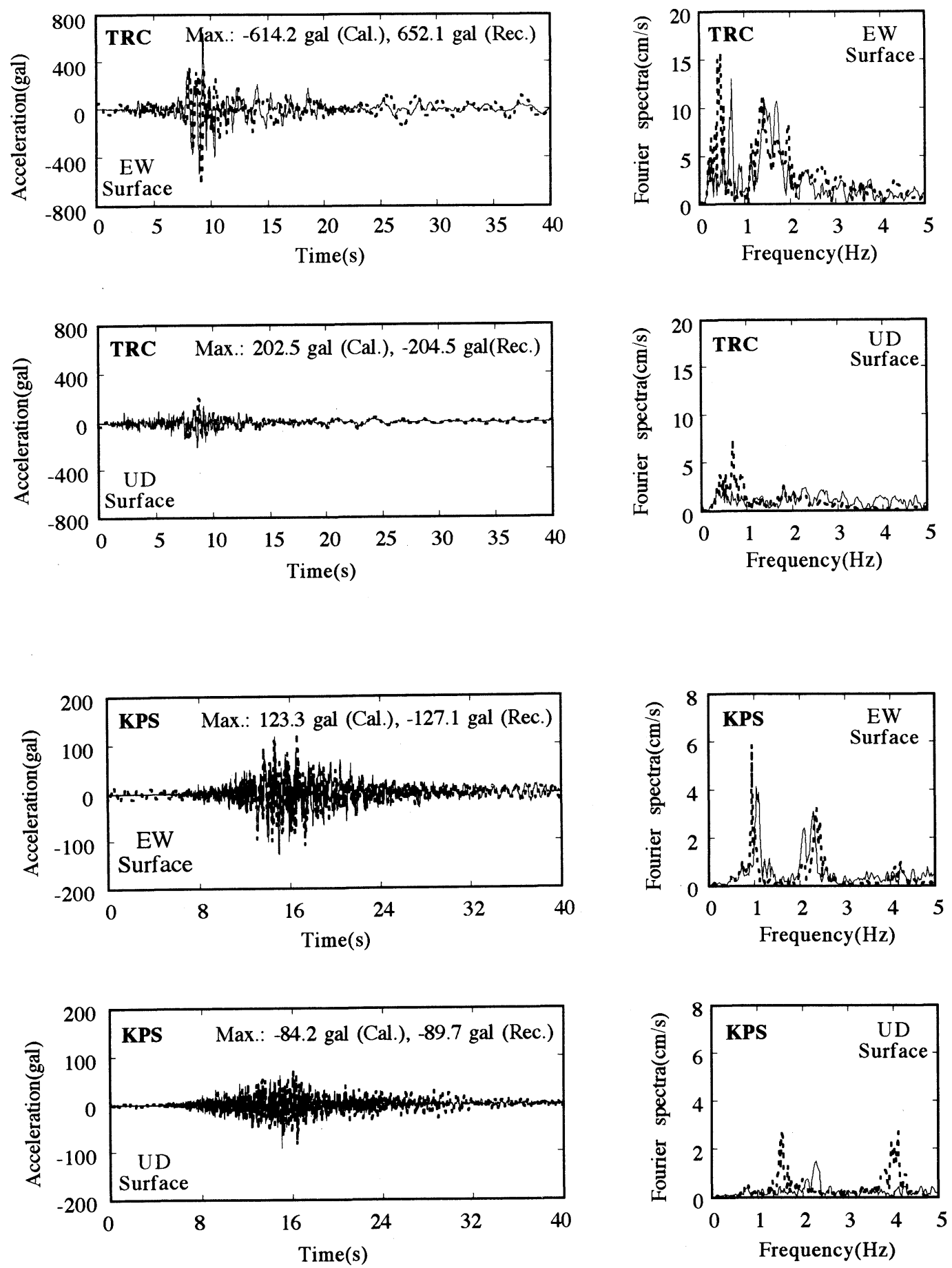

Fig. 7 Comparisons of calculated and recorded accelerations and their Fourier spectra of both horizontal and vertical ground motions at surfaces of TRC and KPS sites. 


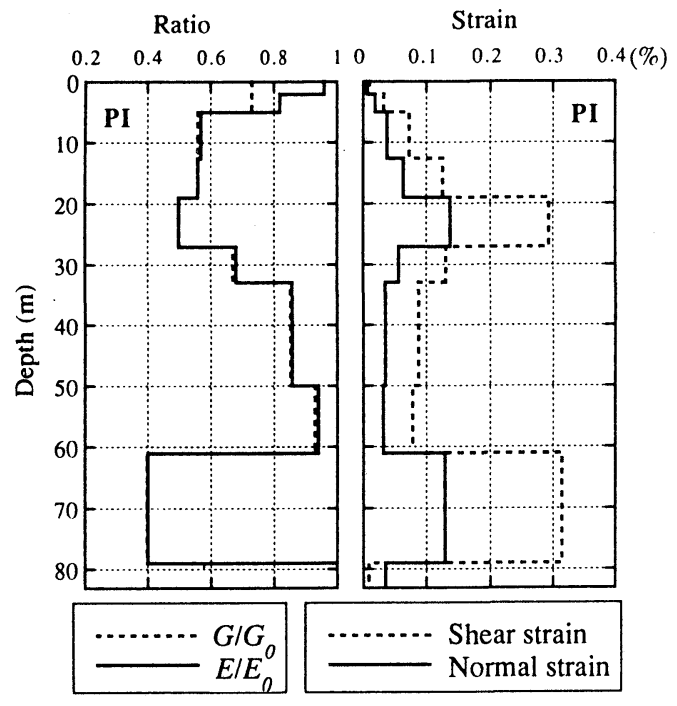

Fig.8 Nonlinear soil properties and strain distributions based on inverse-analysis at PI site

Ratio Strain

$\begin{array}{llllllllllll}0 & 0.2 & 0.4 & 0.6 & 0.8 & 1 & 0 & 0.05 & 0.1 & 0.15 & 0.2 & 0.25(\%)\end{array}$

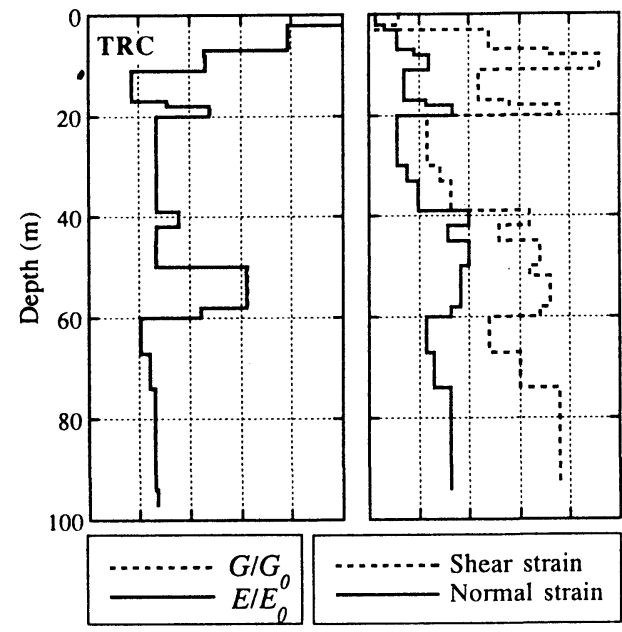

Fig.9 Nonlinear soil properties and strain distributions based on inverse-analysis at TRC site

It indicates that the change of Poisson's ratio under strong ground motion will not cause a distinct difference between $G / G_{o}$ and $E / E_{0}$. Such results are based on the relation of $G$ and $E$ as shown in Eq.(6). This study combines the downhill simplex optimum method and one-dimensional wave propagation theory, the multiple reflection theory, to identify $G$ and $\nu$ so as to estimate $E$ with Eq.(6). Because the value of Poisson's ratio $\nu$ is commonly from 0 to 0.5 , a small change in it will not make a distinct difference. That is why the softening of Young's modulus under strong ground motion is almost as same as that of shear modulus. For engineering purposes, as compared in Figs.6 and 7, the calculated nonlinear re-

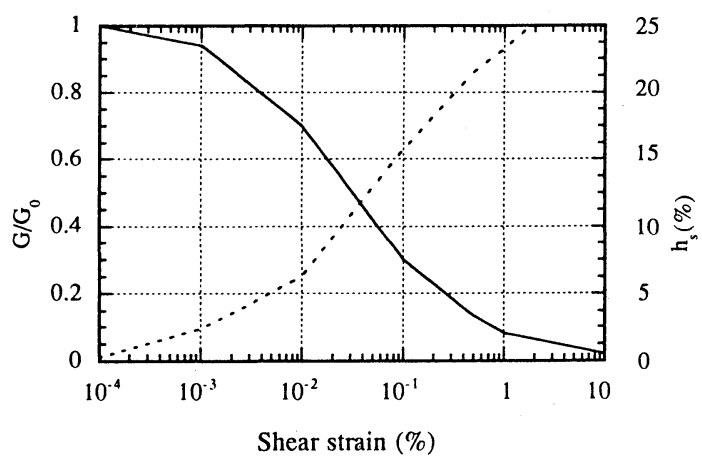

Fig. 10 Shear strain dependency of $G / G_{0}$ and $h_{s}$

sponses of strong ground motions roughly agreed to those of the recorded, and the shear strain-dependent characteristic of shear modulus as shown in Fig.10, which was obtained from the laboratory teats by Seed et $\mathbf{a}^{177}$, can be applied to Young's modulus in order to analyze the nonlinear response of vertical ground motions. However, the shear strain-dependent characteristic of shear damping constant cannot be applied to the normal damping constant. Although this paper conducts an inverse analysis method to identify the normal damping constants at the four sites, it still expects more work on identification of dynamic soil parameters as well as laboratory tests to constitute normal damping constant. It is known that an adoption of a different component of horizontal ground motions will cause a different identification of shear modulus and shear damping constant. As Young's modulus $E$ depends on shear modulus $G$, a proper $E$ is predicated on a proper $G$. To make the calculated results be more precise, it is expected that two or three dimensional analyses are needed to clarify the nonlinear softening in $G$ and $E$.

The softening of shear moduli identified in this paper agrees to that analyzed by Yoshida et al. ${ }^{18)}$. The maximum shear strain distributions calculated with the identified dynamic soil parameters are found to be in correspondence with the softening ratio $G / G_{0}$ according to Fig.10.

\section{CONCLUSIONS}

The study dealt with the nonlinear amplifications of vertical ground motions in the 1995 Hyogoken Nambu earthquake. Four down-hole array records of accelerations obtained during that earthquake were used here to investigate the nonlinear characteristics of amplifications of vertical ground motions in various soil deposits by combining downhill simplex optimum method with multiple reflection theory. The sum of the squared differences between the Fourier 
amplitude spectra of recorded and calculated accelerations was minimized to identify the dynamic soil parameters. the amplification spectra under both strong ground motions and PS logging were compared to evaluate the nonlinear characteristics of soil deposits under the actual earthquake. The identified dynamic soil parameters were used to calculate the nonlinear seismic response of both the horizontal and vertical ground motions. The calculated results were in agreement with those of the recorded. From a view point of engineering, the shear strain-dependent characteristic of shear modulus as shown in Fig.10 ${ }^{17)}$ can be applied to Young's modulus to analyze the nonlinear response of vertical ground motions. Further work on identification and laboratory tests is expected to constitute the strain-dependency of normal damping constant.

ACKNOWLEDGMENT: The authors would like to express their sincere gratitude to Mr. Youichi KATO of the Technical Research Center of Kansai Electric Power Company and the Kansai Earthquake Observation Research Association for supplying us with the down-hole array records data.

\section{REFERENCES}

1) Hardin, B.O. and Drnevich, V.P.: Shear modulus and damping in soils measurement and parameter effects, Jour. SMED, ASCE, Vol.98, No.SM6, pp.603 624, 1972.

2) Tatsuoka, F., Iwasaki, T., Yoshida, S., Fukushima, S. and Sudo, H.: Shear modulus and damping by drained tests on clean sand specimens reconstitued by various methods, Soils and Foundations, Vol.19, No.1, pp.39 54, 1979.

3) Tatsuoka, F., Iwasaki, T. and Takaki, Y.: Hysteretic damping of sands under cyclic loading and its relation to shear modulus, Soils and Foundations, Vol.18, No.2, 1978.

4) Zhai, E., Miyajima, M. and Kitaura, M.: Study of amplification of vertical ground motion using inverse-analysis to determine dynamic soil parameters, J. Structural Eng., Vol.42A, pp.573 579, 1996.

5) Sato, K., Kokusho, T., Matsumoto, M. and Yamada, E.: Nonlinear seismic response and soil property during strong motion, Special Issure of Soils and Foundations, pp.41 52, 1996.
6) Osaki, Y.:New Introduction to Earthquake Spectral Analysis, Kajima Press, 1994 (in Japanese).

7) Toki, K.: New Serial Civil Eng.-11, Earthquake-proof Analysis for Structures, Gihodo Press, 1991 (in Japanese).

8) Ota, H.: The application-1 of optimum method to earthquake engineering, J. Japan Society of Architecture, No.229, pp. 35 41, 1975 (in Japanese).

9) Honda, H., Kojima, K. and Arai, K.: Back-analysis of dynamic soil parameters based on actual accelerations during earthquake, J. Japan Society of Civil Engineers, No.517/II -31, pp.125 133, 1995 (in Japanese).

10) Tsujihara, O., Sawada, T. and Tanidaka, H.: Identification of ground dynamic properties according to array observations, J. Structrural Eng., Vol.36A, pp.747 756,1990 (in Japanese).

11) Tsujihara, O., Sawada, T., Hirao, K. and Okamoto, Y.: The Influence of smoothness of fourier spectra on identification precision of ground shear velocity and $\mathrm{Q}$ value,J.Structrural Eng., Vol.39A, pp.783 792, 1993 (in Japanese).

12) Tsujihara, O., Sawada, T. and Hirao, K.: Comparison of nonlinear optimum method applied to ground identification during earthquake, J. Japan Society of Civil Engineers, No.489/I-27, pp.277-280, 1994 (in Japanese).

13) Sawada, T., Tsujihara, O., Hirao, K. and Okamoto, Y.: Development of partial identification of ground shear velocity and Q value, J. Japan Society of Civil Engineers, No.495/1-28, pp.111 118, 1994 (in Japanese).

14) Nelder, J.A. and Mead, R.: A Simple Method for Function Minimization, Computer J., Vol.7, pp.308 313, 1965.

15) Dixon, L.C.W.: Nonlinear Optimization, St Paul's House, Warwick Lane, London, 1972.

16) Imai, T.: $P$ and $S$ wave velocities of the ground in Japan, Proc. 9th ICSMFE, 1977.

17) Seed, H.B. and Idress, I.M.: Soil Moduli and Damping Factors for Dynamic Response Analysis, Report No. EERC7010, Earthquake Engineering Research Center, University of Califoria, Berkeley, 1970.

18) Yoshida, N., Suetomi. I., Nakamura. S. and Kiku. H.: Nonlinear soil property in the Hyogoken Nambu earthquake, Proc. Symp. Great Hanshin Earthquake Disaster, pp.117 125, 1996 (in Japanese).

\section{5 年兵庫県南部地震における地盤の非線形挙動による上下動増幅}

\section{隻 恩地・宮島昌克・北浦 勝}

1995 年兵庫県南部地震の際に得られた 4 地点の鉛直アレー観測記録に基づき，上下地震動の非線形增 幅特性を検討した。本研究では，重複反射理論に最適化手法であるDOWNHILL SIMPLEXを合わせることに よって動的な地盤定数を同定し，水平動および上下動の非線形地震応答を解析した．さらに，同定された動 的な地盤定数を P S 検層の結果と比較することによって，とくに，上下地震動に関する地盤定数の強震時の 非線形特性を明らかにした。 